\title{
Increased risk of falls, fall-related injuries and fractures in people with type 1 and type 2 diabetes - a nationwide cohort study
}

Citation for published version (APA):

Rasmussen, N. H., Dal, J., den Bergh, J. V., de Vries, F., Jensen, M. H., \& Vestergaard, P. (2021). Increased risk of falls, fall-related injuries and fractures in people with type 1 and type 2 diabetes - a nationwide cohort study. Current Drug Safety, 16(1), 52-61.

https://doi.org/10.2174/1574886315666200908110058

Document status and date:

Published: 01/01/2021

DOI:

10.2174/1574886315666200908110058

Document Version:

Publisher's PDF, also known as Version of record

\section{Document license:}

Taverne

Please check the document version of this publication:

- A submitted manuscript is the version of the article upon submission and before peer-review. There can be important differences between the submitted version and the official published version of record.

People interested in the research are advised to contact the author for the final version of the publication, or visit the DOI to the publisher's website.

- The final author version and the galley proof are versions of the publication after peer review.

- The final published version features the final layout of the paper including the volume, issue and page numbers.

Link to publication

\footnotetext{
General rights rights.

- You may freely distribute the URL identifying the publication in the public portal. please follow below link for the End User Agreement:

www.umlib.nl/taverne-license

Take down policy

If you believe that this document breaches copyright please contact us at:

repository@maastrichtuniversity.nl

providing details and we will investigate your claim.
}

Copyright and moral rights for the publications made accessible in the public portal are retained by the authors and/or other copyright owners and it is a condition of accessing publications that users recognise and abide by the legal requirements associated with these

- Users may download and print one copy of any publication from the public portal for the purpose of private study or research.

- You may not further distribute the material or use it for any profit-making activity or commercial gain

If the publication is distributed under the terms of Article $25 \mathrm{fa}$ of the Dutch Copyright Act, indicated by the "Taverne" license above, 


\title{
Increased Risk of Falls, Fall-related Injuries and Fractures in People with Type 1 and Type 2 Diabetes - A Nationwide Cohort Study
}

\author{
Nicklas Højgaard Rasmussen ${ }^{1}$, Jakob Dal ${ }^{2}$, Joop van den Bergh ${ }^{3,4,5,6}$, Frank de Vries ${ }^{7,8,9}$, Morten \\ Hasselstrøm Jensen ${ }^{10}$ and Peter Vestergaard ${ }^{1}$
}

\begin{abstract}
${ }^{\prime}$ Steno Diabetes Center North Denmark, Aalborg University Hospital, Denmark ${ }^{2}$ Department of Endocrinology, Aalborg University Hospital, Denmark ${ }^{3}$ School for Nutrition and Translational Research in Metabolism (NUTRIM), Maastricht University, Maastricht, The Netherlands $;{ }^{4}$ Department of Internal Medicine, Division of Rheumatology, Maastricht University Medical Center + , Maastricht, The Netherlands, ${ }^{5}$ Department of Internal Medicine, VieCuri Medical Center, Venlo, The Netherlands, ${ }^{6}$ Faculty of Medicine and Life Sciences, Hasselt University, Hasselt, Belgium, ${ }^{7}$ Department of Clinical Pharmacy and Toxicology, Maastricht University Medical Center+, Maastricht, The Netherlands, ${ }^{8}$ Cardiovascular Research Institute Maastricht (CARIM), Maastricht University, Maastricht, The Netherlands, ${ }^{9}$ Division of Pharmacoepidemiology and Clinical Pharmacology, Utrecht Institute of Pharmaceutical Sciences, Utrecht, The Netherlands; ${ }^{.0}$ Department of Health Science and Technology, Aalborg University, Denmark
\end{abstract}

\begin{abstract}
Introduction: People with diabetes could have an increased risk of falls as they show more complications, morbidity and use of medication compared to the general population. This study aimed to estimate the risk of falls and to identify risk factors associated with falls in people with diabetes. The second aim was to estimate fall-related injuries, such as lesions and fractures, including their anatomic localization in people with diabetes compared with the general population.

Methods: From the Danish National Patient Register, we identified people with Type 1 Diabetes (T1D) $(n=12,975)$ Type 2 Diabetes (T2D) $(n=407,009)$. The cohort was divided into two groups, with respective control groups matched on age and sex (1:1). All episodes of people hospitalized with a first fall from 1996 to 2017 were analyzed using a Cox proportional-hazards model. Risk factors such as age, sex, diabetic complications, a history of alcohol abuse and the use of medication were included in an adjusted analysis. The incidence rate, incidence rate difference and incidence rate ratio (IRR) of falls and the anatomic localization of fall-related injuries as lesions and fractures were identified.
\end{abstract}

ARTICLE HISTORY

Received: April 01, 2020 Revised: July 08,2020 Accepted: July 23, 2020 DOI $10.2174 / 1574886315666200908110058$
Results and Discussion: The cumulative incidence, of falls requiring hospital treatment, was $13.3 \%$ in T1D, $11.9 \%$ in T2D. In the adjusted analysis, T1D and T2D were associated with a higher risk of falls [T1D, Hazard Ratio (HR): 1.33 (95\% CI: 1.25 - 1.43), T2D, HR: 1.19 (95\% CI:1.16 - 1.22), respectively]. Women [group 1, HR 1.21 (CI:95\%:1.13 - 1.29), group 2, HR 1.61 (CI:95\%:1.58-1.64)], aged $>65$ years [groups 1 , HR $1.52(\mathrm{CI}: 95 \%: 1.39-1.61)$, group 2 , HR 1.32 (CI:95\%:1.58-1.64)], use of selective serotonin receptor inhibitors (SSRI) [group 1, HR 1.35 (CI:95\%:1.1.30 - 1.40), group 2, HR 1.32 (CI:95\%:1.27-1.38)], opioids [group 1, HR 1.15 (CI:95\%:1.12 - 1.19), group 2, HR 1.09 (CI:95\%:1.05-1.12)] and a history of alcohol abuse [group 1, HR 1.77 (CI:95\%:1.17 - 2.15), group 2, HR 1.88 (CI:95\%:1.65-2.15)] were significantly associated with an increased risk of falls in both groups. The IRR of fall-related injuries as hip, radius, humerus and skull/facial fractures were higher in people with T2D than controls [IRR 1.02 (CI:95\%:1.01-1.04), IRR 1.39 (CI:95\%: 1.18-1.61), IRR 1.24 (CI:95\%: 1.12-1.37) and IRR 1.15 (CI:95\%:1.07-1.24)]. People with T1D had an IRR of hip fractures [IRR: 1.11 (CI:95\%:1.11 $1.23)]$.

Conclusion: People with diabetes have an increased risk of first fall and a higher incidence of fall-related injuries, including fractures. Advanced aging and sex are non-modifiable risk factors, whereas diabetes, the use of SSRIs and opioids and alcohol abuse could be potentially modifiable risk factors for falls. Gaining information on risk factors for falls could guide the management of diabetes treatment, i.e., choice of drugs, which enables us to improve treatment, particularly in people with a high risk of falls and fractures associated with high mortality.

Keywords: Type 1 diabetes, type 2 diabetes, falls, fall-related injuries, lesions, fractures.

\footnotetext{
*Address correspondence to this author at the Steno Diabetes Center North, Aalborg University Hospital, Denmark; E-mail: nicklas.rasmussen@rn.dk
} 


\section{INTRODUCTION}

Falls and fall-related injuries are associated with an increased risk of morbidity and mortality [1].The World Health Organisation defines a fall as an event, which results in a person coming to rest inadvertently on the ground or floor or other lower-level [2]. Approximately 20\% of people aged $>65$ years and $50 \%$ of residents in aged care facilities fall annually, often repeatedly [3, 4]. Among Nordic citizens, falls are the most frequent unintended fatal incident $[5,6]$. The most common injuries associated with falls are fractures and lesions. Falling and osteoporosis are the main determinants of fractures that constitute an increasing public health burden in aging societies [7]. In particular, type 1 diabetes (T1D) and type 2 diabetes (T2D) have been associated with an increased risk of fractures compared to the general population [8-11]. In a recent meta-analysis, the relative risk of any fracture in people with T1D was 3.16 (95\% Confidence Interval [CI]:1.51-6.63), but lower among people with T2D [1.19 (95\% CI:1.11-1.27)] [10, 12]. The increased risk of fractures may be related to decreased bone biomechanical competence from impaired mineralization and bone turnover, a deterioration of collagen and increased loss of calcium in the urine [13-15].

Data on falls among people with diabetes are scarce. Previous studies have suggested an association between falls and diabetes [16-18]. A meta-analysis by Yang et al. found an increased risk of falls in older people with diabetes compared with people without diabetes [RR 1.64 (95\% CI: 1.27-2.11)], whereas the Maastricht study reported similar fall rates in young and well-treated people with T2D compared with healthy people $[17,18]$. The first study population was limited by only including older people ( $>60$ years) and the second by only including people with well-regulated diabetes. Numerous risk factors for falls could, however, be more prevalent in people with real-life diabetes, e.g., balance and gait disturbances, visual disability, changes in body composition as sarcopenia, use of drugs and alcohol, depression and diabetic complication, which could result in injuries as fractures at different anatomic localization [11]. Gaining information on risk factors for falls could guide the management of diabetes treatment, i.e., the choice of drugs, which could improve treatment outcomes, particularly in people with a high risk of falls and fractures. This study aimed to estimate the risk of falls and to identify risk factors associated with increased falls in people with diabetes compared with the general population. The second aim was to estimate fall-related injuries, including lesions and fractures and their anatomic localization in people with diabetes compared with the general population.

\section{MATERIALS AND METHODS}

\subsection{Source of Data}

Data were extracted from the Danish National Patient Registry (DNPR). In Danish registries, people are identified by a unique CPR number [19]. This enabled us to link national data on hospital-diagnoses from the DNPR to the pre- scribed drug from the register of Medicinal Products Statistics of the Danish Medicines Agency to identify all people with diabetes residing in Denmark. The DNPR tracks every hospital admission in Denmark since 1977, recording dates of admission and discharge. The registry covers $99.4 \%$ of all discharge records from Danish hospitals. It covers all inpatient contacts, outpatient visits to the hospital, outpatient visits to clinics and emergency rooms [20]. Physicians use the Danish version of the International Classification of Diseases (ICD) ICD-8 (from 1977 onwards) and 10th revision (ICD-10) (from 1994 onwards) as part of the National Health Service Classification System (SKS) to code diagnoses. SKS keeps track of diagnoses, symptoms, health problems and other causes of patient associated contacts with the health services. Information about drug use came from The National Pharmacological Database by the Danish Medicines Agency, which is a nationwide register of drugs sold after 1996 [21].

\subsection{Study design and Population}

The study was carried out using a retrospective cohort design. The cohort was comprised of all people older than 20 years of age admitted to hospitals in Denmark between the $1^{\text {st }}$ of January 1996 until the $31^{\text {st }}$ of December 2017. Fig. (1) shows the numbers and inclusion of people. The cohort was divided into two groups with respective control groups matched on age and sex (1:1); people with T1D $(n=12,975)$ and people with T2D $(n=407,009)$. People were stratified into T1D or T2D based on codes from the ICD-10 and drug treatment according to the Anatomical Therapeutical Chemical (ATC) classification system. People with T1D were classified by at least one DE10 (type 1 diabetes mellitus) ICD-10 code and at least one A10A (insulins and analogs) and no A10B (blood glucose-lowering drugs, excl. insulins) ATC codes. They were classified as T2D if they had at least one DE11 (type 2 diabetes mellitus) ICD-10 code and an A10B (blood glucose-lowering drugs, excl. insulins) or A10A ATC code. The index date for people with T1D and T2D was set to the date of the first redeemed prescription of A10A or A10B, respectively. Each person was followed-up from his index date until the end of data collection $(31$ December 2017), death, the date of emigration or the date of the outcome of interest, whichever came first. Each control person was assigned the index date of his matched person with T1D or T2D.

\subsection{Outcome and Exposures}

The primary outcome was a person hospitalized with a first registered event of a fall as the main contact after the start of follow-up and risk factors associated with falls. From 1996, a fall was registered as "fall at ground level" [SKS code: EUS00] and "fall from a higher to a lower level" [SKS code: EUS01]. From 2004 an ongoing fall was registered as "fall at the same level, from less or higher than 1 meter, unspecified high, other, unspecified" (SKS-codes: EUHE00-09). Risk factors were; diabetic complications (diabetic nephropathy [ICD-10: DE102, DE112]diabetic retinopathy [ICD10: DE103, DE113], diabetic neuropathy [ICD-10: DE104, DE114], peripheral cardiovascular complications to diabetes [ICD-10: DE105, DE1145], multiple complications 


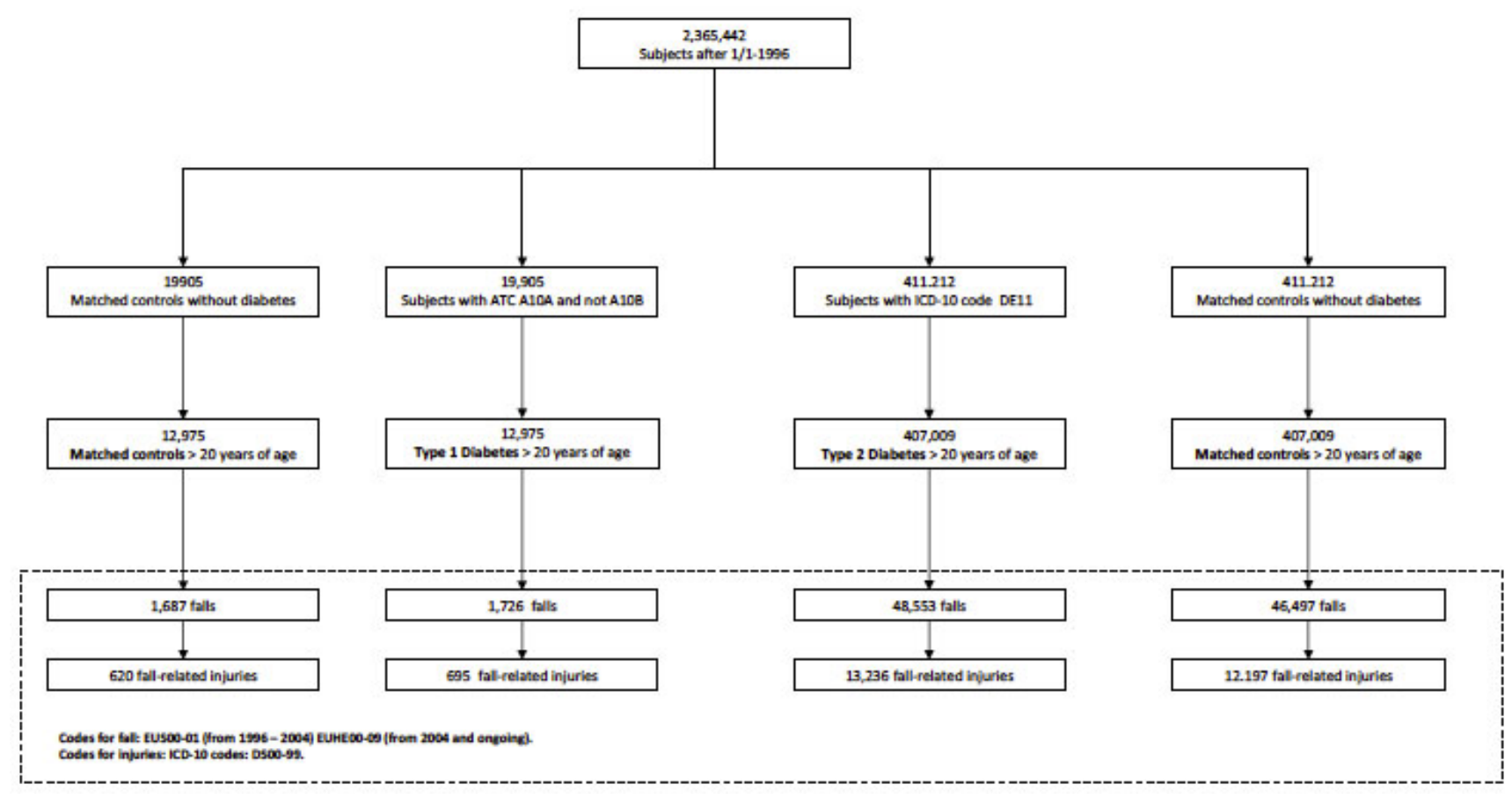

Fig. (1). The flow of inclusion and number of people enrolled in the study.

to diabetes [ICD-10: DE107, DE117 or $>1$ of the mentioned complications] and other complications to diabetes [ICD-10: DE106, DE108, DE116, DE118]), drug (opioids [ATC code: N02A], selective serotonin receptor inhibitors [SSRIs, ATC code: N06AB] and anxiolytics [ATC code: N05B]) and a history of alcohol abuse ([CD-10 code: DF10, DZ721]. Diabetic complications were included at the time of the index date. Dispensing of opioids, SSRIs and anxiolytics was included at least three months before the start of follow-up to ensure a current redeemed prescription.

A second outcome was to estimate the anatomic localization of fall-related injuries. A fall-related injury was defined as a first registered fall together with an external injury event, which was registered as "lesions and fractures" [DS00-99] and comprised of; "lesion or fracture of foot and ankle" [SKS code: DS90-99, DS920-929], "lesion or fractures of hand" [SKS code: DS60-69, DS620-629], "lesion or fracture of hip and femur" [SKS code: DS70-79, DS720-29], "lesion or fracture of the radius" [SKS code: DS50-59, DS520-29], "lesion or fracture of the humerus" [SKS code: DS40-49, DS420-29], "lesion or fracture of the pelvis" [SKS code: DS30-39, 320-329], "lesion of fracture of the skull/face" [SKS code: DS00-09, DS002-029] and "lesions of fracture of the thorax" [SKS-code: DS20-29, DS220-229].

\subsection{Statistical analyses}

A histogram and a qq-plot were used to examine continuous variables for normal distribution. If data were not normally distributed, log transformation was applied. Descrip- tive statistics were presented with a mean or percentage of people with a p-value to show statistical significance. Data was tested using an un-paired T-test to compare variables within the groups. Non-parametric data were expressed as median (range). The Wilcoxon rank-sum test was used to compare nonparametric data within the groups.

A Cox-proportional hazards model was applied to analyze the adjusted and unadjusted effect of falls with T1D and T2D versus controls. Covariates and risk factors in the adjusted model included sex, age, diabetes duration, diabetic complications, a history of alcohol abuse and the use of SSRIs, opioids, and anxiolytics. The Cox-proportional hazards assumption was checked by a parallel log-log transformation of the two survival curves and by a proportional fitted survival curve.

The incidence rates (IR), incidence rate difference (IRD) and the incidence rate ratios (IRR) of the first fall, fall-related injury events as lesions and fractures at specific anatomic localization were estimated from the index-date to the first event of fall or fall-related injury for people with T1D or T2D compared to controls.

The analyses were conducted in STATA version 16.0. The significance level was set at a p-value of less than 0.05 for two-sided testing.

\section{RESULTS}

Table 1 shows the characteristics of people with T1D $(n=12,975), T 2 D(n=407,009)$ and the matched controls at the index-date. The mean age was lower in people with T1D 
Table 1. Characteristics at baseline for people with T1D and sex- and age-matched (group 1) and T2D and sex- and age-matched (group 2) enrolled in this study.

\begin{tabular}{|c|c|c|c|c|c|c|}
\hline & Group 1 & \multicolumn{5}{|c|}{ Group 2} \\
\hline Variable & T1D & Controls & $\mathrm{P}$ & T2D & Controls & $\mathrm{P}$ \\
\hline Number of people & 12,975 & 12,975 & Matched & 407,009 & 407,009 & Matched \\
\hline \multicolumn{7}{|c|}{$\operatorname{Sex}(\%)$} \\
\hline Women & $4,780(36.8)$ & $4,781(36.8)$ & Matched & $201,718(49.6)$ & $201,718(49.6)$ & Matched \\
\hline Men & $8,195(63.2)$ & $8,196(63.2)$ & Matched & $205,291(50.4)$ & $205,291(50.4)$ & Matched \\
\hline Age, years (mean or median) & 49.3 & 49.3 & Matched & 58.2 & 58.2 & Matched \\
\hline \multicolumn{7}{|c|}{ Age interval, (\%) } \\
\hline Age $>20$ and age $<65$ & $9,841(75.85)$ & $9,841(75.85)$ & Matched & $256,232(62.95)$ & $256,232(62.95)$ & Matched \\
\hline Age $>65$ & $3,134(24.15)$ & $3,134(24.15)$ & Matched & $150,777(37.05)$ & $150,777(37.05)$ & Matched \\
\hline Exposure time, years (mean or median) & 7.55 & 9.71 & $<0.001$ & 7.60 & 8.31 & $<0.001$ \\
\hline \multicolumn{7}{|c|}{ Falls (\%) } \\
\hline All falls & $2,500(19.3)$ & $2,346(18.0)$ & $<0.001$ & $67,600(16.6)$ & $63,759(15.70)$ & $<0.001$ \\
\hline First fall from diagnosis & $1,726(13.3)$ & $1,687(13.0)$ & $<0.001$ & $48,553(11.9)$ & $46,497(11.42)$ & $<0.001$ \\
\hline \multicolumn{7}{|c|}{ A history of diabetic Complications (\%) } \\
\hline Cardiovascular & $98(0.7)$ & 0 & - & $1,637(0.4)$ & 0 & - \\
\hline Nephropathies & $97(0.6)$ & 0 & - & $1,416(0.3)$ & 0 & - \\
\hline Neuropathy & $77(0.6)$ & 0 & - & $1,801(0.4)$ & 0 & - \\
\hline Retinopathy & $45(0.3)$ & 0 & - & $482(0.1)$ & 0 & - \\
\hline Multible & $88(0.7)$ & 0 & - & $927(0.2)$ & 0 & - \\
\hline Others & $665(5.0)$ & 0 & - & $8,125(2.0)$ & 0 & - \\
\hline \multicolumn{7}{|c|}{ Medication prior to baseline (\%) } \\
\hline Opioids & $1,057(8.2)$ & $173(1.3)$ & $<0.001$ & $27,486(6.8)$ & $8,624(2.1)$ & $<0.001$ \\
\hline Anxiolytics & $446(3.4)$ & $158(1.2)$ & $<0.001$ & $14,530(3.6)$ & $5,788(1.4)$ & $<0.001$ \\
\hline SSRIs & $353(2.7)$ & $129(1.0)$ & $<0.001$ & $16,449(4.0)$ & $6,292(1.5)$ & $<0.001$ \\
\hline Opioids and Anxiolytics & $247(1.9)$ & $31(0.2)$ & $<0.001$ & $4,805(1.2)$ & $1,281(0.3)$ & $<0.001$ \\
\hline SSRIs and Opioids & $156(1.3)$ & $23(0.2)$ & $<0.001$ & $4,993(1.2)$ & $1,297(0.3)$ & $<0.001$ \\
\hline SSRIs and Anxiolytics & $75(0.6)$ & $23(0.2)$ & $<0.001$ & $3,331(0.8)$ & $1,109(0.3)$ & $<0.001$ \\
\hline SSRIs, Opioids and Anxiolytics & $62(0.5)$ & $6(0.0)$ & $<0.001$ & $1,498(0.4)$ & $319(0.1)$ & $<0.001$ \\
\hline A history of alcohol abuse (\%) & $83(0.6)$ & $10(0.01)$ & $<0.001$ & $823(0.2)$ & $379(0.01)$ & $<0.001$ \\
\hline
\end{tabular}

(49 years) than people with T2D (58 years). A higher proportion of men than women had T1D $(63.2 \%)$, but the sex distribution was balanced in T2D (50.5\%). Between 10 and 15 percent of all people suffered a first fall during the years of exposure $(\mathrm{T} 1 \mathrm{D}=13.3 \%$ vs control $=13.0 \%, \mathrm{p}=<0.001$ and $\mathrm{T} 2 \mathrm{D}=11.9 \%$ vs control $=11.42 \%, \mathrm{p}<0.001)$. History of diabetic complications was low at baseline, but similar among people with T1D and T2D. The use of opioids was 3- to 6-fold higher $(\mathrm{T} 1 \mathrm{D}=8.2 \%$ vs controls $=1.3 \%, \mathrm{p}=<0.001$ and $\mathrm{T} 2 \mathrm{D}=6.8 \%$ vs controls $=2.1 \%, \mathrm{p}<0.001)$. People with T1D $(0.6 \%)$ showed a higher proportion of previous diagnoses of alcohol abuse than T2D (0.01\%).

The Cox proportion assumption was not violated (Table 2). In the adjusted analysis, both T1D and T2D were associated with an increased risk of falls [T1D, HR 1.33 (CI:95\%:1.25 - 1.43) and T2D, HR 1.19 (CI:95\%:1.16 $1.22)$, respectively]. In both groups, women were more likely to suffer from a fall compared to men [group 1, HR 1.21 (CI:95\%:1.13 - 1.29), group 2, HR 1.61 (CI:95\%: 1.58-1.64)]. No significant association was seen regarding diabetic complications at baseline and the risk of falls in either group [group 1, HR 0.96 (CI95\%:0.81-1.21), group 2, HR 1.04 (CI95\%:0.96-1.10)]. Recent use of SSRIs was associated with falls in both groups [group 1, HR 1.35 (CI:95\%:1.30 - 1.40), group 2, HR 1.32 (CI:95\%:1.27 - 1.38)], while recent use of opioids yielded an HR 1.15 (CI:95\%:1.12 - 1.19) in group 1 and HR 1.09 (CI:95\%:1.05 - 1.12) in group 2, respectively. Concomitant use of SSRIs and opioids further increased the risk of falls in both groups [group 1, HR 1.92 (CI95\%:1.31-2.84), group 2 HR 1.60 [(CI95\%:1.49-1.73)]. However, a similar association was not seen with the recent use of anxiolytics. A previous history of alcohol abuse showed a significant increase in the risk of falls [group $1 \mathrm{HR}$ 1.77 (CI:95\%:1.17 - 2.15), group 2, HR 1.88 (CI95\%:1.65-2.15)].

Table 3 shows the IR, IRD and the IRRs of the first falls and fall-related injuries including lesions and fractures in people with T1D and T2D compared to controls. This showed a higher difference in incidence per 1,000 person years (PYs) in people with T1D and T2D for a first fall and fall-related injuries (T1D, IRD 12.2 and 6.23, $\mathrm{p}<0.001$, T2D, IRD 5.25 and $3.36, \mathrm{p}<0.001$ ). Also, a higher incidence 
Table 2. Adjusted and unadjusted results from the Cox regression analysis for people with T1D and sex- and age-matched (group 1) and T2D and sex- and age-matched (group 2) and the risk of falls.

\begin{tabular}{|c|c|c|c|c|}
\hline \multirow[b]{2}{*}{ Exposure } & \multicolumn{2}{|c|}{ Group 1} & \multicolumn{2}{|c|}{ Group 2} \\
\hline & HR $(95 \% C I)$ & $\mathbf{P}$ & HR $(95 \% C I)$ & $\mathbf{P}$ \\
\hline \multicolumn{5}{|l|}{ Unadjusted risk of falls } \\
\hline T1D & $1.19(1.15-1.34)$ & $<0.001$ & - & - \\
\hline $\mathrm{T} 2 \mathrm{D}$ & - & - & $1.09(1.07-1.1)$ & $<0.001$ \\
\hline Controls & 1 & - & 1 & - \\
\hline \multicolumn{5}{|l|}{ Adjusted risk of falls } \\
\hline T1D & $1.33(1.25-1.43)$ & $<0.001$ & - & - \\
\hline $\mathrm{T} 2 \mathrm{D}$ & - & - & $1.19(1.16-1.22)$ & $<0.001$ \\
\hline Controls & 1 & - & 1 & - \\
\hline \multicolumn{5}{|l|}{ Age } \\
\hline Age $>65$ & $1.52(1.39-1.61)$ & $<0.001$ & $1.32(1.30-1.35)$ & $<0.001$ \\
\hline Age $>20<65$ & 1 & - & 1 & - \\
\hline \multicolumn{5}{|l|}{ Sex } \\
\hline Women & $1.21(1.13-1.29)$ & $<0.001$ & $1.61(1.58-1.64)$ & $<0.001$ \\
\hline Male & 1 & - & 1 & - \\
\hline A history of diabetic complications & $0.96(0.81-1.21)$ & 0.465 & $1.04(0.96-1.10)$ & 0.056 \\
\hline \multicolumn{5}{|l|}{ A history of medication } \\
\hline SSRI & $1.35(1.30-1.40)$ & $<0.001$ & $1.32(1.27-1.38)$ & $<0.001$ \\
\hline Opiods & $1.15(1.12-1.19)$ & $<0.001$ & $1.09(1.05-1.12)$ & $<0.001$ \\
\hline Anxiolytics & $0.97(0.89-1.33)$ & 0.184 & $0.98(0.89-1.12)$ & 0.184 \\
\hline SSRI and Opiods & $1.92(1.31-2.84)$ & 0.001 & $1.60(1.49-1.73)$ & $<0.001$ \\
\hline SSRI and anxiolytics & $0.93(0.57-1.53)$ & 0.794 & $1.15(1.07-1.21)$ & 0.012 \\
\hline Anxiolytics and opiods & $0.93(0.68-1.27)$ & 0.654 & $1.03(0.97-1.10)$ & 0.329 \\
\hline SSRI, anxiolytics and opiods & $1.09(1.05-1.21)$ & $<0.001$ & $1.14(1.08-1.21)$ & $<0.001$ \\
\hline A history of Alcohol abuse & $1.77(1.17-2.15)$ & 0.006 & $1.88(1.65-2.15)$ & $<0.001$ \\
\hline
\end{tabular}

Table 3. Incidence rates and incidence rate ratios for fall-related injuries and the anatomic localization of fractures in T1D and T2D compared to controls.

\begin{tabular}{|c|c|c|c|c|c|c|c|c|c|c|}
\hline & $\begin{array}{c}\text { T1D } \\
\mathbf{N}=12,97 \\
5\end{array}$ & $\begin{array}{c}\text { Controls } \\
\mathrm{N}=12,975\end{array}$ & \begin{tabular}{|c|} 
IR T1D \\
/1,000 \\
PYs
\end{tabular} & $\begin{array}{c}\text { IR Con- } \\
\text { trols } \\
/ 1,000 \mathrm{PYs}\end{array}$ & $\begin{array}{l}\text { IRR T1D /Con- } \\
\text { trols }(95 \% \text { CI) }\end{array}$ & $\begin{array}{c}\text { T2D } \\
N=407,009\end{array}$ & $\begin{array}{c}\text { Controls } \\
\mathrm{N}=\mathbf{4 0 7 , 0 0 9}\end{array}$ & \begin{tabular}{|c|} 
IR T2D \\
$/ 1,000$ \\
PYs
\end{tabular} & \begin{tabular}{|c|} 
IR Con- \\
trols \\
$/ 1,000 \mathrm{PYs}$
\end{tabular} & $\begin{array}{c}\text { IRR T2D/Controls } \\
(95 \% \mathrm{CI})\end{array}$ \\
\hline First fall & 1,726 & 1,687 & 68.75 & 56.55 & $1.21(1.13-1.29)$ & 48,553 & 46,497 & 64.56 & 59.31 & $1.09(1.07-1.12)$ \\
\hline $\begin{array}{l}\text { First fall-related } \\
\text { injury }\end{array}$ & 695 & 620 & 36.6 & 29.2 & $1.25(1.12-1.39)$ & 13.236 & 12.197 & 23.59 & 21.04 & $1.10(1.07-1.12)$ \\
\hline \multicolumn{11}{|c|}{ Fall-related injuries by anatomic localization } \\
\hline Ankle and foot & 84 & 93 & 5.51 & 4.62 & $1.19(0.98-2.07)$ & 1,270 & 1,185 & 2.24 & 2.18 & $1.03(0.93-1.11)$ \\
\hline Hand & 70 & 76 & 4.44 & 3.97 & $1.11(0.90-1.19)$ & 1,416 & 1,342 & 2.60 & 2.48 & $1.04(0.96-1.10)$ \\
\hline Hip and femur & 101 & 86 & 4.20 & 3.61 & $1.16(0.83-1-63)$ & 2,037 & 1,750 & 3.35 & 3.10 & $1.08(1.04-1.11)$ \\
\hline Radius & 78 & 69 & 4.09 & 3.27 & $1.25(0.88-1.75)$ & 1,699 & 1,480 & 3,29 & 2.39 & $1.37(1.27-1.47)$ \\
\hline Humerus & 92 & 68 & 4.03 & 3.83 & $1.05(0.75-1.45)$ & 1,505 & 1,412 & 2.73 & 2.43 & $1.12(1.04-1.20)$ \\
\hline $\begin{array}{c}\text { Pelvis and lower } \\
\text { back }\end{array}$ & 28 & 20 & 1.18 & 1.20 & $0.98(0.52-1.80)$ & 580 & 489 & 0.94 & 0.94 & $1.00(0.88-1.13)$ \\
\hline Skullfacial & 114 & 106 & 6.04 & 4.73 & $1.27(0.96-1.68)$ & 2,422 & 2,285 & 4.33 & 3.82 & $1.13(1.06-1.20)$ \\
\hline $\begin{array}{l}\text { Thorax and up- } \\
\text { per-back }\end{array}$ & 25 & 35 & 1.89 & 1.20 & $0.57(0.91-2.71)$ & 538 & 515 & 0.99 & 0.86 & $1.14(0.98-1.32)$ \\
\hline \multicolumn{11}{|c|}{ Fractures by anatomic localization } \\
\hline Ankle and foot & 21 & 12 & 0.71 & 0.90 & $0.78(0.35-1.67)$ & 180 & 207 & 0.30 & 0.40 & $0.75(0.56-1.30)$ \\
\hline
\end{tabular}




\begin{tabular}{|c|c|c|c|c|c|c|c|c|c|c|}
\hline Hand & 28 & 24 & 1.42 & 1.20 & $1.18(0.65-2.11)$ & 474 & 437 & 0.84 & 0.76 & $1.10(0.96-1.25)$ \\
\hline Hip and femur & 58 & 47 & 2.78 & 2.49 & $\mathbf{1 . 1 1}(\mathbf{1 . 0 2}-\mathbf{1 - 2 3})$ & 1,421 & 1,207 & 2.33 & 2.28 & $\mathbf{1 . 0 2}(\mathbf{1 . 0 1}-\mathbf{1 . 0 4})$ \\
\hline Radius & 56 & 41 & 2.43 & 2.23 & $1.04(0.67-1.59)$ & 1,313 & 1,069 & 1.81 & 1.31 & $\mathbf{1 . 3 9}(\mathbf{1 . 2 8}-\mathbf{1 . 5 1})$ \\
\hline Humerus & 61 & 29 & 1.71 & 2.23 & $0.65(0.40-1.03)$ & 774 & 803 & 1.55 & 1.25 & $\mathbf{1 . 2 4}(\mathbf{1 . 1 2}-\mathbf{1 . 3 7})$ \\
\hline $\begin{array}{c}\text { Pelvis and lower } \\
\text { back }\end{array}$ & 7 & 9 & 0.29 & 0.12 & $2.29(0.44-14.77)$ & 205 & 196 & 0.01 & 0.11 & $0.90(0.62-1.35)$ \\
\hline Skull/facial & 87 & 83 & 3.49 & 2.75 & $1.26(0.86-1.87)$ & 1,107 & 1,160 & 2.80 & 2.42 & $\mathbf{1 . 1 5}(\mathbf{1 . 0 7}-\mathbf{1 . 2 4})$ \\
\hline $\begin{array}{c}\text { Thorax and upper } \\
\text { back }\end{array}$ & 8 & 12 & 0.71 & 0.34 & $2.06(0.77-5.43)$ & 136 & 121 & 0.18 & 0.14 & $1.27(0.92-1.68)$ \\
\hline
\end{tabular}

of first falls in people with diabetes [T1D, IRR 1.21 (CI:95\%:1.13 - 1.29), T2D, IRR 1.09 (CI:95\%:1.07 - 1.12)] was seen. The incidence of fall-related injuries was higher in both T1D and T2D [T1D, IRR 1.16 (CI:95\%:1.08 - 1.24), T2D, IRR 1.12 (CI:95\%:1.09 - 1.15)]]. Regarding fall-related injuries at specific anatomic localization, people with T1D had a higher incidence of hip and femur fractures [IRR: 1.11 (CI:95\%:1.11 - 1.23)]. The IRR of fall-related injuries as hip, radius, humerus and skull/facial fractures were higher in people with T2D than controls [IRR 1.02 (CI:95\%:1.01-1.04), IRR 1.39 (CI:95\%: 1.18-1.61), IRR 1.24 (CI:95\%: 1.12-1.37) and IRR 1.15 (CI:95\%: 1.07-1.24)]. Non-significant increased risk of fractures was seen at other anatomic localizations.

\section{DISCUSSION}

In this population-based retrospective cohort study, we used nationwide data to estimate the incidence of falls, risk factors and fall-related injures, including fractures for falls in people with diabetes during the period 1996-2017 that required acute medical attention. The risk of falls was increased in people with T1D and T2D compared to matched controls. Several risk factors such as age, female gender, recent use of SSRIs or opioids and a history of alcohol abuse were associated with an increased risk of falls. The incidence of hip, femur, radius, humerus and head lesions and fractures was significantly increased in T2D.

\subsection{Fall-related injuries}

A high overall incidence was reported as approximately $10-15 \%$ of all people with diabetes had suffered a hospitalized fall within the 20 years study period. However, the accurate estimate of falls is most likely underestimated due to unreported falls not leading to hospitalization or falls with another origin than injuries, e.g., lipothymia or epilepsy (SKS codes: DR55 "fainting and collapse", DG20 "epilepsy"). The ICD-10 codes are categorized differently than fall-related injuries and the correlation with falls is not yet validated. The majority of falls in a nursing home are unwitnessed [22]. Falls could be unreported if the resident was able to rise without assistance, then the fall or injury would not be reported. Our findings of a higher incidence of falls in people with diabetes resemble the findings of Vestergaard et al., who reported higher risks of fractures, especially at the hip $[10,12]$. In particular, hip and femoral fractures in people with diabetes were also shown to have an increased incidence rate ratio in this study. Especially, hip and femoral fractures are associated with an increased risk of mortality and are a huge burden to society [23]. Head injuries were al- so increased and the anatomic localization could indicate that people with T2D suffer more from episodes with loss of conscience, arrhythmia, or hypoglycemia. Furthermore, head injuries or traumatic brain injuries are associated with complications as intracerebral hemorrhage, brain damage, and meningitis, which require complex treatment [24]. Pelvic injuries are often associated with falls in the elderly population and have a high complication rate and risk of ruptures of vessels, which is the primary cause of death [25, $26]$. To fend-off a fall, a well-balanced postural control system is needed. Fractures at the humerus and radius could indicate another falling mechanism from a lack of reflexes, e.g., neuropathy or a compromised cardiovascular response, hence falling on the side.

\subsection{Risk factors}

Drugs used in people with diabetes could be a potentially modifiable risk factor for falls $[27,28]$. Treatment with SSRIs, opioids, and anxiolytics was commonly used amongst people with diabetes. SSRIs have been associated with a 1.4- to 6-fold increased risk of falls [29]. Furthermore, treatment with SSRIs in combination with opioids has shown an increased risk of developing serotonergic syndrome, hyponatremia, and an increase in blood sugar, unappropriated effects on the central nervous system or cardiovascular system that could increase the risk of falls by postural imbalance [30]. Treatment with SSRIs is mainly used to treat depression and is rarely indicated in the treatment of diabetic neuropathy [31]. In addition, only a few people were diagnosed at baseline with neuropathy, hence this was probably not the indication for the prescription, but most likely depression. A meta-analysis showed a higher level of depressive symptoms resulted in a great risk of falling [RR 1.52 (95\% CI:1.19- 1.84)] [32]. Another recent meta-analysis showed that one out of four people with T2D experienced depression, and depressive symptoms were found to be consistently associated with falls in older people [33]. Hence, the excessive use of SSRIs could be an expression of depression in people with diabetes in this study.

Up to $50 \%$ of people with diabetes develop diabetic neuropathy and about $20 \%$ develop painful neuropathic [34]. Opioids are frequently used as a last resort against painful neuropathy. In a recent case-control study of people older than 65 years, the use of opioids one month before a fall was significantly associated with a greater risk of suffering a fall with hip fracture [OR 4.49 (95\% CI:2.72-7.42)] [35]. These 
findings correspond to the findings in this study and add to the long list of side-effects from opioid use, which should be considered carefully, especially in the management of people with a chronic illness like diabetes.

The use of anxiolytics showed no significant association with falls, though anxiolytics may increase the risk of falling due to the risk of occurrence of drowsiness, muscle weakness, change in stability, vertigo, and hypotension [36]. However, the indication for anxiolytics varies from sleeping disorders, epilepsy, drug addiction to epilepsy and neurological disputes and differs in concentration, mechanism of action, and duration [36]. Hence, identifying the entities and use of the drugs, specific types of anxiolytics could also have increased the risk of falls in this study.

In this study, the combination of different drugs additionally increased the risk of falls. In general, there is clear evidence that polypharmacy increases the risk of falls [37]. A study by Huang et al. showed that regimens including 4 or more prescribed drugs were significantly associated with an increased risk of falling [4-5 drugs, HR 1.22 (95\% CI: 1.04 1.43)], [6-7 drugs, 1.33 (95\% CI: 1.12 - 1.58), [>7 drugs, 1.59 (95\% CI: 1.34, 1.89)] [38]. People with T2D take, on average, nine prescription drugs compared to four prescription drugs in people without diabetes [16]. Polypharmacy might be an indication of intensified treatment due to a worsening of the diabetes condition. However, the awareness of particular harmful drugs, as included in this study, should be considered carefully in the management of people with diabetes.

The elderly population is associated with numerous risk factors for falls, and diabetes seems to add to the increased risk, but also at a younger age. Especially, people with T1D are diagnosed at a younger age, i.e., longer diabetes duration and risk of developing complications that require pharmacological treatment and episodes of hypoglycemia.

People with a previous history of alcohol abuse were highly associated with an increased risk of falls. Amongst others, alcohol increases the risk of hyponatremia, dehydration, liver diseases, and neuropathy, which affects the chemical and compensatory mechanisms necessary to avoid a fall [39]. Besides the risk of falls, several mechanisms exist whereby alcohol might also adversely affect the fracture risk. A recent study showed a 3-fold increase of fractures in people with diabetes associated with an alcohol-related diagnosis [40]. Over time, alcohol decreases bone turnover due to malabsorption, malnutrition, and metabolic effects from alcohol resulting in calcium deficits, which could increase the risk of fractures [41, 42]. The negative effects of extensive use of alcohol could be more pronounced in people with diabetes compared to people without diabetes. Therefore, alcohol should be considered an important risk factor of falls and fractures in diabetes; especially, when considered the higher proportion of people with diabetes with a history of alcohol abuse compared with the general population. However, the proportion of alcohol abuse was probably underestimated compared with other study findings [43].
Complications to diabetes were low at the time of diagnosis and a non-significant association with the risk of falls was seen. The proportion of people who develop diabetic complications as reduced eyesight, neuropathic pain, or cardiovascular increases over time and could potentially be risk factors for falls.

Following the present results, others have found injury-causing falls, leading to medical treatment to be overrepresented in women compared with men [44, 45]. Women also have an increased risk of fractures, probably due to hormonal factors like a lack of estrogen following menopause [25, $46,47]$. Hormonal factors may also affect the loss of muscle mass, and in several studies, it has been shown that women tend to lose muscle strength faster than men [48, 49]. Several studies have reported a decrease in muscle mass, strength, and function in people with diabetes compared with people without diabetes $[50,51]$. If loss of balance occurs, preventing a fall may become challenging due to inadequate muscle response and fall-related injuries could increase. Hence, women with diabetes and advanced aging seem to be at a particularly increased risk for falls and fall-related injuries as fractures.

\subsection{Strengths}

This study has several advantages for addressing the association of falls and fractures in diabetes. This cohort allows for population-based estimates of incidences, risk assessments, and characterization of falls in people with diabetes. Besides, matched control groups represent the general population, which allows us to make robust risk estimations. In addition, comprehensive adjustments reduced the confounding risk factors associated with falls as age, sex, alcohol abuse, drugs, diabetes duration and diabetes type. A previous validation study of the accuracy of DNHR records from somatic hospital departments showed that the contact reasons and the injury mechanisms were correctly coded in more than $90 \%$ of the validated records [52].

\section{LIMITATIONS}

In this study, people with T1D and T2D both showed an increased risk of falls compared to controls. However, some limitations have to be considered. Firstly, additional adjustment for body mass index (BMI), other types of drugs, previous falls and fractures were not added to the analysis, due to the restricted access to patient records. In general, underweight is thought to increase the risk of falls due to sarcopenia, fatigue, and malnutrition $[53,54]$. However, the majority of people with diabetes are often overweight, though weight loss often occurs in people with T1D before diagnosis [55].

Secondly, ICD-10 codes were used to identify falls. From 1987 to 2004, all falls were coded according to the NOMESCO (NOrdic MEdico-Statistical COmmittee) injury-code system, which describes the external cause of the injury, place of occurrence of the injury, and the activity performed at the time of injury [56]. From 2004 and onwards, the NOMESCO injury-code system was replaced by other 
SKS-codes, and the validity of fall codes could have been reduced. However, it would probably underestimate the effect of falls. Moreover, $50 \%$ of all fall-related injuries recorded in the DNHR were unspecified according to the activity performed at the time of the fall incident; hence no attempt was made to characterize the fall injury events by this information. Moreover, the activity was not included as an endpoint in this study set-up.

\section{CONCLUSION}

In conclusion, this study showed a high overall incidence of falls in people with diabetes resulting in hospitalization. Besides, several risk factors were associated with falls, like age, female gender, SSRIs, opioids, and a history of alcohol abuse. Hip, radius, humerus and head injuries were more pronounced in people with T2D.

Advanced aging and sex are non-modifiable risk factors, whereas diabetes, drugs, and alcohol abuse could be a potentially modifiable risk factor for falls. Gaining information on risk factors for falls could guide the management of diabetes treatment, i.e., choice of drug, which enables us to improve treatment, particularly in people with a high risk of falls and fractures associated with high mortality.

\section{AUTHOR'S CONTRIBUTION}

NHR has designed the study, did the statistics and drafted the article. MHJ came with valuable input to the study design and statistics and the article writing. PV, FV, JB and JD revised it critically for important intellectual content and gave final approval of the version to be published. All the co-authors have read and approved the final article.

\section{ETHICS APPROVAL AND CONSENT TO PARTICI- PATE}

This was not a clinical trial, and ethics committee approval was not required.

\section{HUMAN AND ANIMAL RIGHTS}

Not applicable.

\section{CONSENT FOR PUBLICATION}

Not applicable.

\section{AVAILABILITY OF DATA AND MATERIALS}

Data are available through Danmarks Statistik (http://www.dst.dk) and all authorized research organizations can apply for access. Access for international researchers can only be gained if they are affiliated to a Danish research organization.

\section{FUNDING}

Declared none.

\section{CONFLICT OF INTEREST}

The author declares no conflict of interest, financial or otherwise.

\section{ACKNOWLEDGEMENTS}

Declared none.

\section{REFERENCES}

[1] Vos T, Barber RM, Bell B, et al. Global Burden of Disease Study 2013 Collaborators. Global, regional, and national incidence, prevalence, and years lived with disability for 301 acute and chronic diseases and injuries in 188 countries, 1990-2013: a systematic analysis for the Global Burden of Disease Study 2013. Lancet 2015; 386(9995): 743-800.

[http://dx.doi.org/10.1016/S0140-6736(15)60692-4] [PMID: 26063472]

[2] Falls https:/www.who.int/news-room/fact-sheets/detail/falls

[3] Thapa PB, Brockman KG, Gideon P, Fought RL, Ray WA. Injurious falls in nonambulatory nursing home residents: a comparative study of circumstances, incidence, and risk factors. J Am Geriatr Soc 1996; 44(3): 273-8.

[http://dx.doi.org/10.1111/j.1532-5415.1996.tb00913.x] [PMID: 8600195]

[4] Tinetti ME, Speechley M, Ginter SF. Risk factors for falls among elderly persons living in the community. N Engl J Med 1988; 319(26): 1701-7.

[http://dx.doi.org/10.1056/NEJM198812293192604] [PMID: 3205267]

[5] Toft AMH, Møller H, Laursen B. The years after an injury: longterm consequences of injury on self-rated health. J Trauma 2010; 69(1): 26-30

[http://dx.doi.org/10.1097/TA.0b013e3181d3cbf2] [PMID: 20622575]

[6] Laursen B, Møller H. Long-term health effects of unintentional injuries in Danish adults. Dan Med J 2012; 59(5): A4423.

[PMID: 22549487]

[7] Cummings SR, Nevitt MC. Study of Osteoporotic Fractures Research Group. Non-skeletal determinants of fractures: the potential importance of the mechanics of falls. Osteoporos Int 1994; 4 (Suppl. 1): 67-70.

[http://dx.doi.org/10.1007/BF01623439] [PMID: 8081063]

[8] Sarodnik C, Bours SPG, Schaper NC, et al. Fracture risk in patients with type 2 diabetes mellitus and possible risk factors: a systematic review and meta-analysis. Osteoporos Int 2018; 18: 427-44.

[9] Janghorbani M, Van Dam RM, Willett WC, Hu FB. Systematic review of type 1 and type 2 diabetes mellitus and risk of fracture. Am J Epidemiol 2007; 166(5): 495-505. [http://dx.doi.org/10.1093/aje/kwm106] [PMID: 17575306]

[10] Shah VN, Shah CS, Snell-Bergeon JK. Type 1 diabetes and risk of fracture: meta-analysis and review of the literature. Diabet Med 2015; 32(9): 1134-42.

[http://dx.doi.org/10.1111/dme.12734] [PMID: 26096918]

[11] Rasmussen NH, Dal J. Falls and Fractures in Diabetes-More than Bone Fragility. Curr Osteoporos Rep 2019; 17(3): 147-56. [http://dx.doi.org/10.1007/s11914-019-00513-1] [PMID: 30915638]

[12] Vestergaard P. Discrepancies in bone mineral density and fracture risk in patients with type 1 and type 2 diabetes--a meta-analysis. Osteoporos Int 2007; 18(4): 427-44.

[http://dx.doi.org/10.1007/s00198-006-0253-4] 17068657]

[13] Starup-Linde J, Vestergaard P. Management of endocrine disease: Diabetes and osteoporosis: cause for concern? Eur J Endocrinol 2015; 173(3): R93-9.

[http://dx.doi.org/10.1530/EJE-15-0155] [PMID: 26243638]

[14] Starup-Linde J, Lykkeboe S, Gregersen S, et al. Bone structure and predictors of fracture in type 1 and type 2 diabetes. J Clin Endocrinol Metab 2016; 101(3): 928-36.

[http://dx.doi.org/10.1210/jc.2015-3882] [PMID: 26756117]

[15] Starup-Linde J, Lykkeboe S, Gregersen S, et al. Differences in biochemical bone markers by diabetes type and the impact of glucose. Bone 2016; 83: 149-55.

[http://dx.doi.org/10.1016/j.bone.2015.11.004] [PMID: 26555635]

[16] Roman de Mettelinge T, Cambier D, Calders P, Van Den Noort- 
gate N, Delbaere K. Understanding the relationship between type 2 diabetes mellitus and falls in older adults: a prospective cohort study. PLoS One 2013; 8(6)e67055

[http://dx.doi.org/10.1371/journal.pone.0067055] [PMID: 23825617]

[17] de Waard EAC, Koster A, Melai T, et al. The association between glucose metabolism status, diabetes severity and a history of fractures and recent falls in participants of 50 years and older-the Maastricht Study. Osteoporos Int 2016; 27(11): 3207-16. [http://dx.doi.org/10.1007/s00198-016-3645-0]

[PMID: 27234668]

[18] Yang Y, Hu X, Zhang Q, Zou R. Diabetes mellitus and risk of falls in older adults: a systematic review and meta-analysis. Age Ageing 2016; 45(6): 761-7. [http://dx.doi.org/10.1093/ageing/afw140] [PMID: 27515679]

[19] Frank L. Epidemiology. When an entire country is a cohort. Science $2000 ; 287(5462): 2398-9$.

[http://dx.doi.org/10.1126/science.287.5462.2398] [PMID: 10766613]

[20] Andersen TF, Madsen M, Jørgensen J, Mellemkjoer L, Olsen JH. The Danish National Hospital Register. A valuable source of data for modern health sciences. Dan Med Bull 1999; 46(3): 263-8. [PMID: 10421985]

[21] Kildemoes HW, Sørensen HT, Hallas J. The Danish National Prescription Registry. Scand J Public Health 2011; 39(7) (Suppl.): $38-41$

[http://dx.doi.org/10.1177/1403494810394717]

[PMID: 21775349]

[22] Dipietro L, Campbell WW, Buchner DM, et al. 2018 PHYSICAL ACTIVITY GUIDELINES ADVISORY COMMITTEE*. Physical Activity, Injurious Falls, and Physical Function in Aging: An Umbrella Review. Med Sci Sports Exerc 2019; 51(6): 1303-13. [http://dx.doi.org/10.1249/MSS.0000000000001942] [PMID: 31095087]

[23] Hopkins RB, Pullenayegum E, Goeree R, et al. Estimation of the lifetime risk of hip fracture for women and men in Canada. Osteoporos Int 2012; 23(3): 921-7.

[http://dx.doi.org/10.1007/s00198-011-1652-8] [PMID: 21557096]

[24] Taylor CA, Bell JM, Breiding MJ, Xu L. Traumatic brain injury-related emergency department visits, hospitalizations, and deaths - United States, 2007 and 2013. MMWR Surveill Summ 2017; 66(9): 1-16

[http://dx.doi.org/10.15585/mmwr.ss6609a1] [PMID: 28301451]

[25] Breuil V, Roux CH, Carle GF. Pelvic fractures: epidemiology, consequences, and medical management. Curr Opin Rheumatol 2016; 28(4): 442-7.

[http://dx.doi.org/10.1097/BOR.0000000000000293] [PMID: 27077891]

[26] Stahel PF, Hammerberg EM. History of pelvic fracture management: a review. World J Emerg Surg 2016; 11: 18

[http://dx.doi.org/10.1186/s13017-016-0075-4]

[PMID: 27148396]

[27] Seppala LJ, Wermelink AMAT, de Vries M, et al. EUGMS task and Finish group on fall-risk-increasing drugs. Fall-Risk-Increasing Drugs: A Systematic Review and Meta-Analysis: II. Psychotropics. J Am Med Dir Assoc 2018; 19(4): 371.e11-7.

[http://dx.doi.org/10.1016/j.jamda.2017.12.098] [PMID 29402652]

[28] Woolcott JC, Richardson KJ, Wiens MO, et al. Meta-analysis of the impact of 9 medication classes on falls in elderly persons. Arch Intern Med 2009; 169(21): 1952-60.

[http://dx.doi.org/10.1001/archinternmed.2009.357] [PMID 19933955]

[29] Antidepressant Prescriptions: An Acute Window for Falls in the Nursing Home https://www.ncbi.nlm.nih.gov/pmc/articles/PMC3202899/

[30] Vestergaard P. Drugs Causing Bone Loss 2019. [http://dx.doi.org/10.1007/164 2019 340]

[31] Javed S, Petropoulos IN, Alam U, Malik RA. Treatment of painful diabetic neuropathy. Ther Adv Chronic Dis 2015; 6(1): 15-28. [http://dx.doi.org/10.1177/2040622314552071] [PMID: 25553239]
[32] Kvelde T, McVeigh C, Toson B, et al. Depressive symptomatology as a risk factor for falls in older people: systematic review and meta-analysis. J Am Geriatr Soc 2013; 61(5): 694-706.

[http://dx.doi.org/10.1111/jgs.12209] [PMID: 23617614]

[33] Khaledi M, Haghighatdoost F, Feizi A, Aminorroaya A. The prevalence of comorbid depression in patients with type 2 diabetes: an updated systematic review and meta-analysis on huge number of observational studies. Acta Diabetol 2019; 56(6): 631-50.

[http://dx.doi.org/10.1007/s00592-019-01295-9] [PMID: 30903433]

[34] Feldman EL, Callaghan BC, Pop-Busui R, et al. Diabetic neuropathy. Nat Rev Dis Prim 2019.

[35] Machado-Duque ME, Castaño-Montoya JP, Medina-Morales DA, Castro-Rodríguez A, González-Montoya A, Machado-Alba JE. Association between the use of benzodiazepines and opioids with the risk of falls and hip fractures in older adults. Int Psychogeriatr 2018; 30(7): 941-6.

[http://dx.doi.org/10.1017/S1041610217002745] [PMID: 29223172]

[36] The Use of Antidepressants, Anxiolytics, and Hypnotics in People with Type 2 Diabetes and Patterns Associated with Use: The Hoorn Diabetes Care Sys https://www-ncbi-nlm-nih-gov.auh.aub.aau.dk/pubmed/28232942

[37] Milos V, Bondesson A, Magnusson M, Jakobsson U, Westerlund T, Midlöv P. Fall risk-increasing drugs and falls: a cross-sectional study among elderly patients in primary care. BMC Geriatr 2014; 14: 40 .

[http://dx.doi.org/10.1186/1471-2318-14-40] [PMID: 24674152]

[38] Huang ES, Karter AJ, Danielson KK, Warton EM, Ahmed AT. The association between the number of prescription medications and incident falls in a multi-ethnic population of adult type-2 diabetes patients: the diabetes and aging study. J Gen Intern Med 2010; 25(2): 141-6.

[http://dx.doi.org/10.1007/s11606-009-1179-2] 19967465]

[39] Paik JM, Deshpande R, Golabi P, Younossi I, Henry L, Younossi $Z M$. The impact of modifiable risk factors on the long-term outcomes of non-alcoholic fatty liver disease. Aliment Pharmacol Ther 2020; 51(2): 291-304.

[http://dx.doi.org/10.1111/apt.15580] [PMID: 31782543]

[40] Starup-Linde J, Gregersen S, Vestergaard P. Associations with fracture in patients with diabetes: a nested case-control study. BMJ Open 2016; 6(2)e009686

[http://dx.doi.org/10.1136/bmjopen-2015-009686] [PMID: 26873048]

[41] Kanis JA, Johansson $\mathrm{H}$, Johnell O, et al. Alcohol intake as a risk factor for fracture. Osteoporos Int 2005; 16(7): 737-42.

[http://dx.doi.org/10.1007/s00198-004-1734-y]

[PMID: 15455194]

[42] Rico: Alcohol and bone disease - Google Scholar https://scholar-google-com.auh.aub.aau.dk/scholar_lookup?author=1990.

[43] Jensen MH, Hejlesen O, Vestergaard P. Risk of major cardiovascular events, severe hypoglycaemia, and all-cause mortality for users of insulin degludec versus insulin glargine U100-A Danish cohort study. Diabetes Metab Res Rev 2020; 36(1)e3225

[http://dx.doi.org/10.1002/dmrr.3225] [PMID: 31647163]

[44] Høidrup S, Sørensen TIA, Grønbaek M, Schroll M. Incidence and characteristics of falls leading to hospital treatment: a one-year population surveillance study of the Danish population aged 45 years and over. Scand J Public Health 2003; 31(1): 24-30. [http://dx.doi.org/10.1080/14034940210134185]

[PMID: 12623521]

[45] Gazibara T, Kurtagic I, Kisic-Tepavcevic D, et al. Falls, risk factors and fear of falling among persons older than 65 years of age. Psychogeriatrics 2017; 17(4): 215-23. [http://dx.doi.org/10.1111/psyg.12217] [PMID: 28130862]

[46] Ensrud KE. Epidemiology of Fracture Risk With Advancing Age. Journals Gerontol Ser A Biol Sci. Med Sci 2013; 68: 1236-42.

[47] Schilcher J, Koeppen V, Aspenberg P, Michaëlsson K. Risk of atypical femoral fracture during and after bisphosphonate use. Acta Orthop 2015; 86(1): 100-7.

[http://dx.doi.org/10.3109/17453674.2015.1004149] [PMID: 25582459] 
[48] Shafiee G, Keshtkar A, Soltani A, Ahadi Z, Larijani B, Heshmat R. Prevalence of sarcopenia in the world: a systematic review and meta- analysis of general population studies. J Diabetes Metab Disord 2017; 16: 21 .

[http://dx.doi.org/10.1186/s40200-017-0302-x] [PMID: 28523252]

[49] Kirchengast S, Huber J. Gender and age differences in lean soft tissue mass and sarcopenia among healthy elderly. Anthropol Anz 2009; 67(2): 139-51.

[http://dx.doi.org/10.1127/0003-5548/2009/0018] [PMID 19739465]

[50] Park SW, Goodpaster BH, Strotmeyer ES, et al. Health, Aging, and Body Composition Study. Accelerated loss of skeletal muscle strength in older adults with type 2 diabetes: the health, aging, and body composition study. Diabetes Care 2007; 30(6): 1507-12.

[http://dx.doi.org/10.2337/dc06-2537] [PMID: 17363749]

[51] Guerrero N, Bunout D, Hirsch S, et al. Premature loss of muscle mass and function in type 2 diabetes. Diabetes Res Clin Pract 2016; 117: 32-8.

[http://dx.doi.org/10.1016/j.diabres.2016.04.011] 27329020]
[52] Schmidt M, Schmidt SAJ, Sandegaard JL, Ehrenstein V, Pedersen L, Sørensen HT. The Danish National Patient Registry: a review of content, data quality, and research potential. Clin Epidemiol 2015; 7: 449-90.

[http://dx.doi.org/10.2147/CLEP.S91125] [PMID: 26604824]

[53] Cruz-Jentoft AJ, Bahat G, Bauer J, et al. Writing Group for the European Working Group on Sarcopenia in Older People 2 (EWGSOP2), and the Extended Group for EWGSOP2. Sarcopenia: revised European consensus on definition and diagnosis. Age Ageing 2019; 48(1): 16-31.

[http://dx.doi.org/10.1093/ageing/afy169] [PMID: 30312372]

[54] Nielson CM, Srikanth P, Orwoll ES. Obesity and fracture in men and women: an epidemiologic perspective. J Bone Miner Res 2012; 27(1): 1-10.

[http://dx.doi.org/10.1002/jbmr.1486] [PMID: 23348758]

[55] Maffeis C, Birkebaek NH, Konstantinova M, et al. SWEET Study Group. Prevalence of underweight, overweight, and obesity in children and adolescents with type 1 diabetes: Data from the international SWEET registry. Pediatr Diabetes 2018; 19(7): 1211-20. [http://dx.doi.org/10.1111/pedi.12730] [PMID: 30033651]

[56] NOMESKO. Nordisk Ulykkesklassifikation, 8. No Title 1987. 